\title{
Single line to ground fault detection and location in medium voltage distribution system network based on neural network
}

\author{
Ahmed K. Abbas', Sumaya Hamad ${ }^{2}$, Nuha A. Hamad \\ ${ }^{1}$ Department of Construction and Projects, University of Anbar, Anbar, Iraq \\ ${ }^{2}$ College of Computer Science and Information Technology, University of Anbar, Anbar, Iraq \\ ${ }^{3}$ University Headquarter, University of Anbar, Anbar, Iraq
}

\begin{tabular}{l} 
Article Info \\
\hline Article history: \\
Received Oct 14, 2020 \\
Revised Jun 1, 2021 \\
Accepted Jun 11, 2021 \\
\hline
\end{tabular}

\section{Keywords:}

EMTP program software

MATLAP's fast-fourier-transform

MV network

$\mathrm{NN}$ algorithm

Single line to ground fault

\begin{abstract}
The aim of this project was to detect and locate the single ground failure lines that occurs in medium voltage (MV) networks on the transmission lines (TL). Compared with anther faults, single line-to-ground (SLG) is the most frequent. The neural network $(\mathrm{NN})$ algorithm was advanced in order to discover and locate SLG faults. The network is simulated through simulated numerous defects at various locations, as well as changing earth resistance from (or $100 \Omega$ ) to TL to gather all of the data. In the electromagnetic transients' program (EMTP) program software, the existing fault have been measured. In addition, the waves were evaluated by utilize MATLAP's fastfourier-transform to calculate the waves of top three of them, On the MV network are fifty hundred faults are simulated all data in the neural network at MATLAB were trained and examined to improve the NN algorithm according to this data. Comparing all the simulated location faults that have been applied with those all locations detected in the $\mathrm{NN}$ algorithm, the overall error between them has been found to be very low and not to exceed 0.7. The Simulink circuit was created from this algorithm and checked in order to predict each failure could occur in the future in the MV network.
\end{abstract}

This is an open access article under the CC BY-SA license.

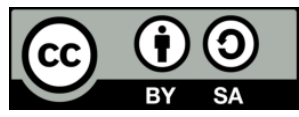

Corresponding Author:

Ahmed K. Abbas

University Headquarter

Department of Construction and Projects

University of Anbar, Anbar, Ramadi, Iraq

Email: Ahmed89at@uoanbar.edu.iq

\section{INTRODUCTION}

The electricity is one of every country's major industries. Commonly (generation, transmission and distribution) are usually three components of each electrical system. They are all important to the whole power system. The power system has been sophisticated more and more over the past few years. The length of transmission lines (TL) in power system are increasingly longer. The TL voltage level is likewise higher and higher. Nonetheless, it is impossible to prevent defects on the transmission line [1]. The safety and stability of the power grid is compromised by such failures. The lengthy the electrical outage, the bigger the harm. Subsequently, the fault site is easily identified and utilities begin to get electricity. The exact detect of the failure point are the faster way to easily repair the defect. Therefore, the failure position appreciation for the transmission system is also important for electrical engineers and utilities, because of a number of reasons such as ionizing air and lightning, the failure of the electrical network happens. That come in touch with wires in the atmosphere, livestock or trees, and salt sprays and contaminations on insulators addition approximately $80 \%$ of the faults in the power network were due to interruption, particularly in the transmission area [2]-[5]. 
In each transmission line (TL), two kinds of faults, balanced fault and unbalanced fault. In addition, referred to as symmetrical and asymmetrical fault [6]. Unbalanced failure is the greatest of incidents on electrical power devices. Furthermore, faults could be classified as shunt and serial faults. Series failures are the kinds of faults that happen in line impedance which does not include that ground or neutral, nor involve linked the phases. Single line to ground fault most common type of shunt fault. There are four types of faults three phase transmission line.

- Single line-to-ground (SLG)

- Line-to line faults (LL)

- Double line-to-ground (DLG) faults

- Balanced three phase faults

For more than 100 years, power systems have been using in service. Cumulative experiences indicate that not every fault is equally probable. The highest common faults is the single-line to ground defects $(\mathrm{L}-\mathrm{G})$, While the fault is the consequence of simultaneous short-circuit among each of three lines, defined as the three phase (L-L-L) fault. Approximately 50 to $80 \%$ of the faults of the single-phase ground defects of the MV medium voltage network is the most prevalent from another faults in distribution network. An analysis in 2010, conducted by Dresden German public utilities, defects found that 75 percent of all faults was single line-ground fault [7]. Moreover, approximately $80 \%$ of the defects were measured implicated just one phase neutral or ground contact only phase [8].

Lately, machine training has rapidly become developed and successfully implemented either to transmitting or distribution system to identify forms of defects [9]. Nevertheless, most research is focused, on finding defects in overhead power transmission [10]-[16] not in the power distribution network. The article has been established a machine-learning algorithm for distribution network identification of defect forms known as the support vector machine (SVM) [17]-[19]. Initial findings from the results of the simulation observed that the suggested approach is easy to learn and that it has reasonable accuracy results. The conventional algorithm cannot produce data as well as location for maintenance purposes in the some electrical systems. Implementation of a fuzzy or NN techniques will become more suitable [20], [21]. Simulation was carried out in the fuzzy logic implementation with a robust member function, where system can detecting and detailed provisions all kinds of shunt faults [22].

\section{TECHNIQUE IMPLEMENTATION}

The alternate transient system (ATP)/electromagnetic transients program (EMTP) will be implemented utilizing to build the MV network [19]. The $20 \mathrm{KV}$ network is built and has numerous branches. The construction of the network needed several electrical elements to be taken according to actual network as (transformer, generators, and transmission lines) [IEEE 34 feeders]. Its network has been configured for (balance and unbalance) load and without load. Then, The NN algorithm has been sophisticated and the Simulink circuit generated to identify any fault could happen in the future on the MV network [23]. A number of steps to develop the NN algorithm are available. Firstly, in MV network numerous faults are simulated with changing resistance fault (RF) and changes of the fault site several times at the same point. Secondly, the current wave fault is analyzed and measures. Two programs have been utilized to gather the data utilized for NN algorithm development. Fault current from current wave was measured utilized ATP/EMTP [24], and the current wave was analysis by utilized fast fourier transfer (FFT) in MATLAB.

\subsection{Design MV network solid1y system}

The medium voltage built in the ATP $20 \mathrm{KV}$ draw consists of a power supply and multiple feeders attached to this power supply. The various network design elements: generator $110 \mathrm{KV}, 50 \mathrm{HZ}$. The following are specified. Transformer $1: 110 \mathrm{KV} / 20 \mathrm{KV}, R P T=1,7424 ; R S T=0.021168 \mathrm{LTP}=231 \mathrm{MH}$; $L T S=2,804$; Transformer 2: $20 \mathrm{KV} / 400 \mathrm{~V}, R L=230 \Omega$ transfer. The network is constructed by ATP draw without load, balance load and unequal load. The RL value LL loads can be calculated based on this equation, Assume $\mathrm{PF}=0.9$

$$
\begin{aligned}
& \mathrm{PF}=\cos \emptyset \rightarrow \emptyset=\cos -1 \mathrm{PF} \\
& \mathrm{RL}=\frac{\mathrm{s}}{\cos \emptyset} \mathrm{XL}=\frac{\mathrm{s}}{\sin \emptyset} \\
& L=2 \times W \times X L \\
& W=2 \times \pi \times F
\end{aligned}
$$

Indonesian J Elec Eng \& Comp Sci, Vol. 23, No. 2, August 2021: 621 - 632 


\subsection{Simulate MV network}

The MV network has been developed, several errors have been simulated over many distances. The key aim of the study is to find every fault position on the MV network by calculating the fault current and evaluating it. In EMTP, the feeder and the fault distances of $7 \mathrm{~km}$ at point 1 after substation at $72 \mathrm{~km}$ at point 29 at the end of branch B9 were simulated with one single line to ground defect. This is the longest branch relative to other branches because of this. The defect resistances often varied from $0 \Omega$ to $100 \Omega$. At $7 \mathrm{~km}, 12$ $\mathrm{km}, 17 \mathrm{~km}, 22 \mathrm{~km}, 32 \mathrm{~km}, 42 \mathrm{~km}, 50 \mathrm{~km}, 57 \mathrm{~km}, 67 \mathrm{~km}$ and $72 \mathrm{~km}$, the distance to the fault was held, and at each position the resistance to the defect increased five times. Each network simulated 50 defects such that all three MV networks that were configured for ATP drawing were simulated for the 150 defects.

\subsection{Fault current wave methods}

The paper focuses on single-line earth loss as when every step interacts with the ground, it's the most common on networks. Thus, without the other branches, the current flows to the ground immediately. When a fault happens on the MV network, the wave for current and voltage switches phase, phase and shape and simple concept of calculating and analyzing the current and voltage wave to recognize the instances of arrival of one or more of these fault waves [25]. Figure 1 shows the current and voltage wave on TL prior following SLG faults.

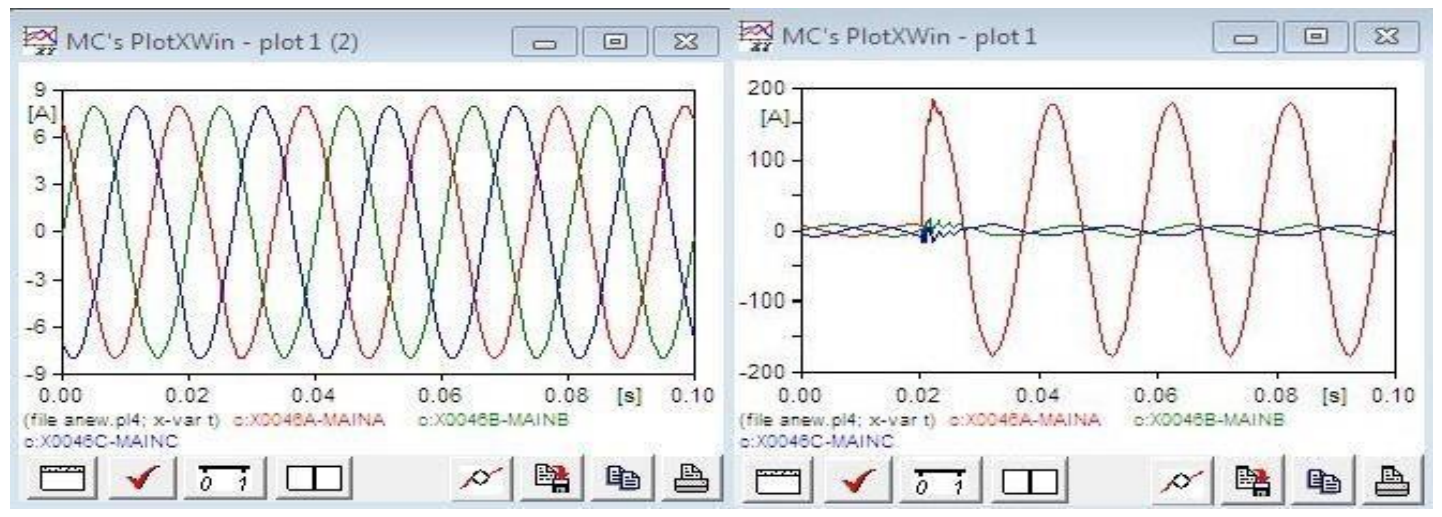

(a)

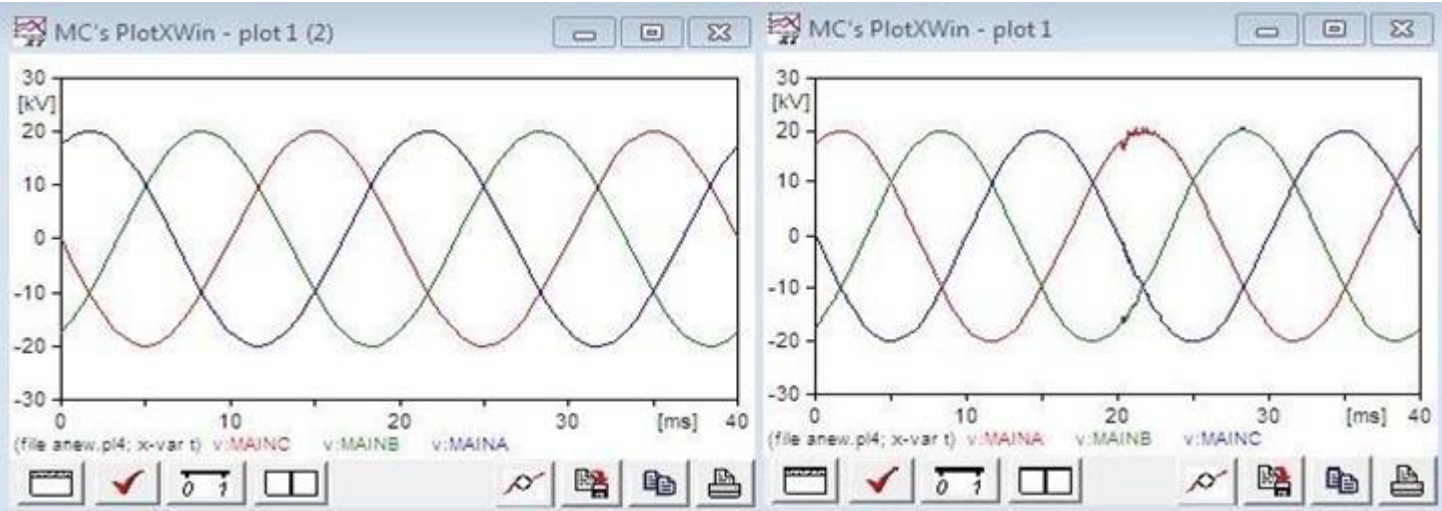

(b)

Figure 1. Before fault and after fault; (a) current wave in MV network and (b) voltage wave in MV network

The current wave changes during current and voltage waves are very large, as compared with the voltage wave, in terms of value and shape. This paper is based on the $\mathrm{NN}$ algorithm for the measurement and analysis of current waves to detect the location of all failures. Wave current is collected from the central ammeter and calculated by means of the ATP/EMTP system for faults replicated in the MV network. There are 150 failures that simulated the data collection on MV network for all forms of load at various distances and resistances. the current value of the fault when the transmission line (TL) balance is calibrated at $0 \mathrm{ohms}$ after $7 \mathrm{~km}$ from the sub-station. 


\subsection{Fast furrier transfer (FFT) in MATLAB}

Fast fourier is commonly used in many scientific, electronics and maths applications, and Fourier 's discrete transforms (DFT) are one of the best-known methods to convert signal from time domain to frequency domain. It is used to effectively track signals with sharp changes, and hence the analysed FFT signal must be stable, which appears to be mysterious transient. A time frequency analysis is important to resolve this issue. FFT is used to determine the amplitude, the phase and the harmonic of current and voltage correlating. In fact, in these equations, the Fourier transforms FT and the fourier transformation (DFT).

$$
F T(f)=\int_{-\infty}^{\infty} x(t) \cdot e^{-j 2 \pi f t} d t
$$

In case of t time, $\mathrm{f}$ shall be frequency, $\mathrm{n}$ and $\mathrm{k}$ will be integer variable parameters, and [ $\mathrm{n}$ ] shall be a sequence of the continuous time signal $\mathrm{x}(\mathrm{t})$ for samples of $\mathrm{N}$, which is obtained in every Ts second. FFT was therefore used to obtain the best possible data for detecting the location of the error in accordance with the current wave measurement and analysis. In MATLAP, FFT must be used to transfer a wave from a time domain to a frequency domain with code. Then the original wave is transferred to the upper three first domains, from the time domain to the frequency domain. Figure 2(a) and (b) shows the discrepancy of the original EMTP wave to the same wave after it was transformed by using FFT in MATLAB to frequency domain.

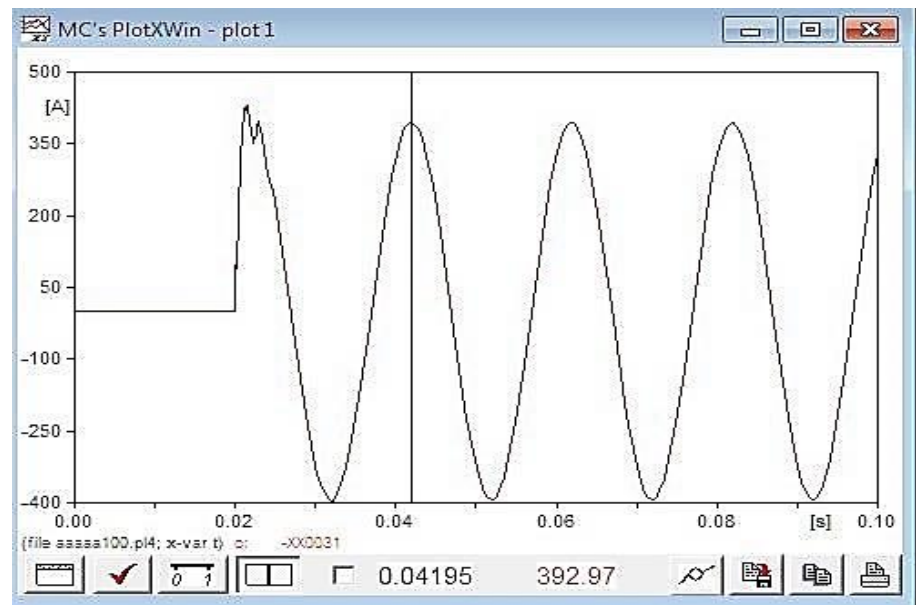

(a)

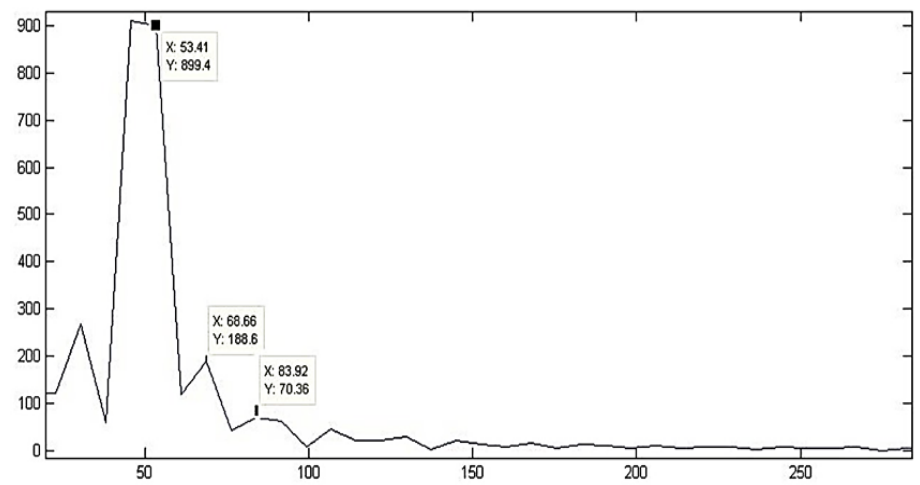

(b)

Figure 2. Difference between the original current wave and wave after using FFT; (a) current wave measured in EMTP and (b) current wave after use FFT

\subsection{Artificial neural network}

The most common form is that a neural network is the machine that is infectious in modeling the way that the brain carries out a particular task or function, normally using electronic elements or simulating the network in software on a digital computer. In comparison to a fault place approach for a radian power delivery network, ANN-based procedure measurement of the direction of the fault in the power grid is used to identify waves of voltage and current at every malfunction site. A single-core pipe system with cores and 
underground sheaths is built in the sending end as an line cable constant (LCC) backup routine for the ATP applications. The transient signal is then broken down into its modal components. In the second step, the calculation and interpretation of fault waves was used for useful details.

For any input sequence, the network generates the right response back. This paper analyses all data obtained from all existing fault waves calculating and evaluating at the target position and generates a simulated circuit. To find any defective location on the MV network in the future, all defects on the MV network have been simulated. As matrix as input results, the evaluated results should also contain the goals as seen in equations. Artificial neural network One approach to resolve protection issues because it could be trained with the potential to learn off line information [26]. It is demonstrated that the outcome of modeling of fault identification utlizing artificial neural network is accurate as the designed to operate time is a few $\mathrm{ms}$ just after occurrence of the fault [27].

\section{SIMULATION RESULTS}

One of the key goals of identifying and locating the malfunction in sub-station control (TL) is to minimize the time, to break the line off the network and not impact other lines, and to pinpoint the position of the flaw to restore, and immediately attach the fault to the network. First, the fault process ATP/EMTP system would be observed immediately. Secondly, the fault is located. Three measures are taken to create a Simulink Circuit NN algorithm to detect position for actual failure:

- The use, as a temporary simulator, of alternative temporary program ATP/EMTP. Using fast furrier transfer (FFT) in MATLAB

- Using neural network $(\mathrm{NN})$ in MATLAB

\subsection{Fault phase detection}

At the beginning of the transmission line, an ammeter has been used to dispose of the current passengers in this branch for a control room as well as the main meter to compares the current transmitters in the main line and branch. If SLG happens at any point, the current from TL directly reaches the ground without going through any branch. This means that in another branch the current becomes zero. We replicated a defect with the ATP system on the main line and at the end of the section. When evaluating the current flowing, the division of the error is known. Figure 3(a) indicates the error simulated for the ATP system on the main line in a TL section, as the current flowed straight from the main line to the earth without any branch. The current only came from the main ammeter and all ammeter branches read zero. When the fault on the branch (B8) was simulated, the flow of the power flowed from the main line into the earth. The main line ammeter and branch have thus read the same value and other metres, have read zero as shown in Figure 3(b).

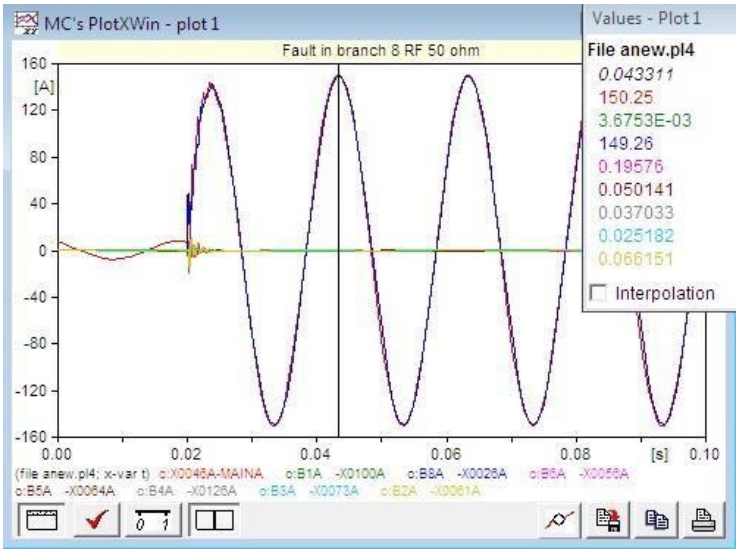

(a)

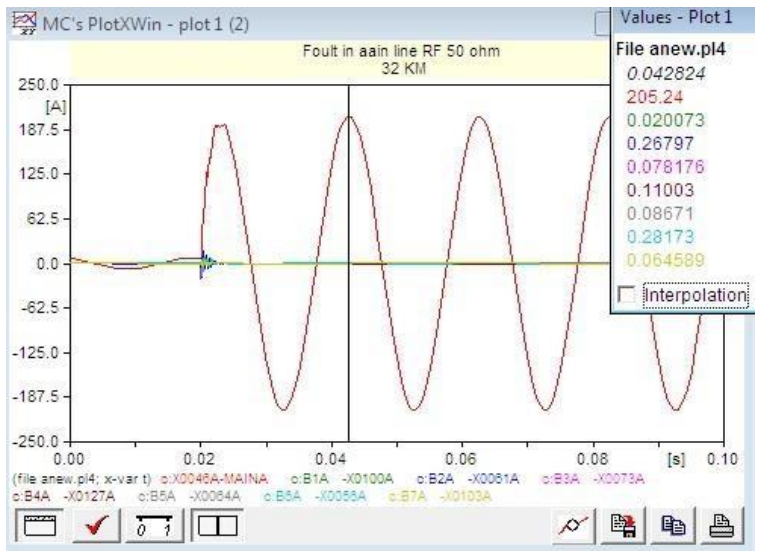

(b)

Figure 3. These figures are; (a) fault on main line and (b) fault on branch

The current flow in all meters recognizes the current flow in the main line and the remaining branches when the system is in normal conditions. But if a failure occurred on the main side, only +0 current fault is interpreted by the main meter. As the present travels along the main line, without moving branches directly to the bottom. The present flows from the main line and branch to land when the fault occurs in either section. Thus, as seen in the table above, the primary ammeter and the ammeter in this industry are read existing errors. 


\subsection{Locate fault location}

Many failures in the balancing, unbalanced load, and unloading MV network have been simulated with ATP/EMTP in ten locations $(7,12,17,27,32,42,50,57,67$, and 71) to locate the defaults in the location. Kilometers at any location and simulated all failures on main supply with changing resistance fault (RF) five times. The fault values of resistance $(0,25,50,75$, and 100) are ohm. The inability to construct and improve NN algorithms was replicated fifty hundred times in all load cases on TL to achieve the maximum index.

The measurement and analyzing wave fault current during the fault phase is achieved through the use of alternative ATP/EMTP and quick furrier transfer (FFT) in MATLAB in two steps. Of any fault simulated in TL with ATP / EMTP system for all 150, TL simulated faults, the actual fault was determined from the central ammeter [28]. Figure 4 illustrates how the current defect of the current wave can be measured when the balance load on TL occurs after $7 \mathrm{~km}$ of the substation with defect resistance $(0,25) \mathrm{ohm}$.

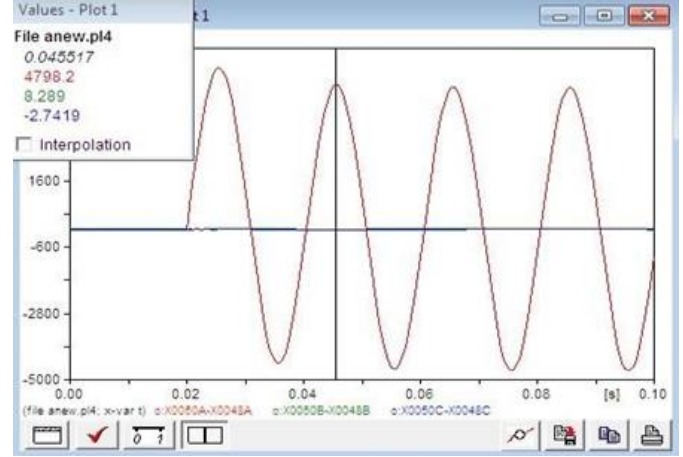

(a)

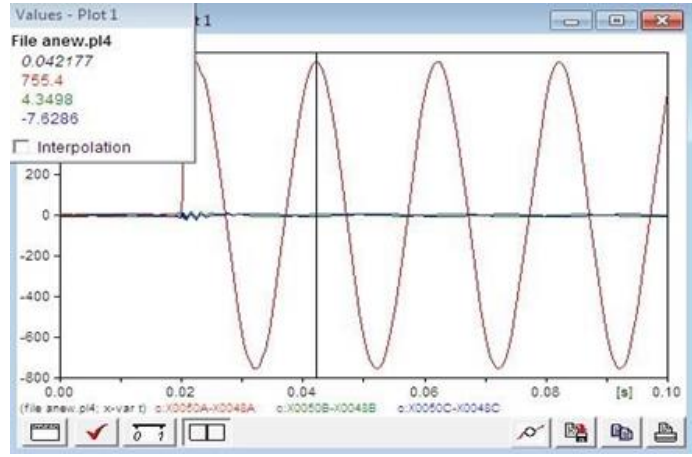

(b)

Figure 4. Displays current fault at $7 \mathrm{~km}$ at balance load; (a) $\mathrm{RF}=0 \Omega$ and (b) $\mathrm{RF}=25 \Omega$

Table 1 shows the current fault at $7 \mathrm{~km}$ for all kinds of network, balance, unbalance and without load with different value of resistance $(0,25,50,75$ and 100) ohm on TL. The current fault for the remaining distances has also been calculated. From the results, we can see that the load on the TL has very few effects. We found that the current loss decreases according to distance from substation and magnitude of RF as seen in Figure 5 after all existing waves have been calculated.

Table 1. The current failure shows balance, unbalance and without load at $7 \mathrm{~km}$

\begin{tabular}{lccccc}
\hline \multirow{2}{*}{ Load } & 0 & 25 & 50 & 75 & 100 \\
\hline Balance & 4798.2 & 755.5 & 393.25 & 266.57 & 202.1 \\
Unbalance & 4798.1 & 755.09 & 392.91 & 266.26 & 201.78 \\
With out & 4798.1 & 755.2 & 393.04 & 266.38 & 201.9 \\
\hline
\end{tabular}

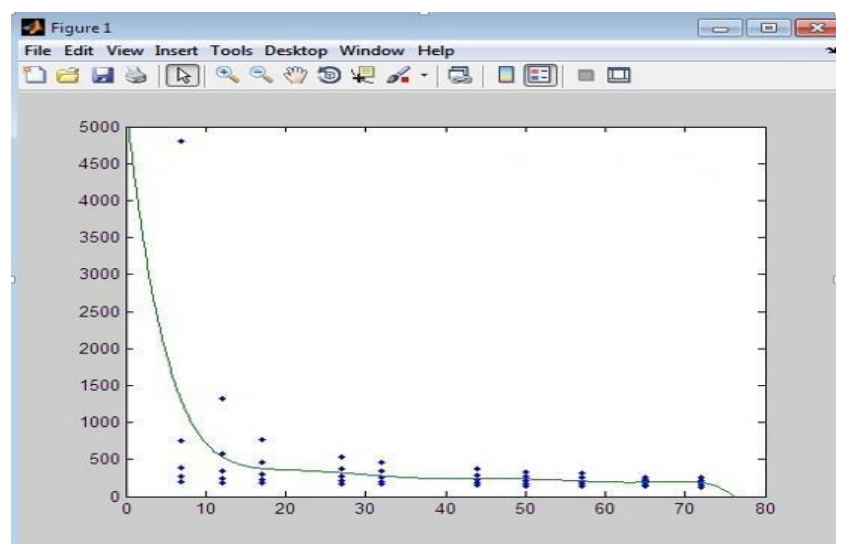

Figure 5. Relationship between fault location and fault current 


\subsection{Analyze fault current wave}

For the wave current which the main ammeter in TL obtains to obtain more data. In order to calculate higher first three domains in this wave, the current wave has been analyzed via FFT in MATLAB 150 failures previously simulated on TL. Therefore, 150 have been FFT analyzed. We would then show how to calculate the first high domain. Figure 6(a) and (b) shows when the failure occurred in the $\mathrm{RF}(25$ and $50 \Omega)$ at $7 \mathrm{~km}$ from the balancing station.

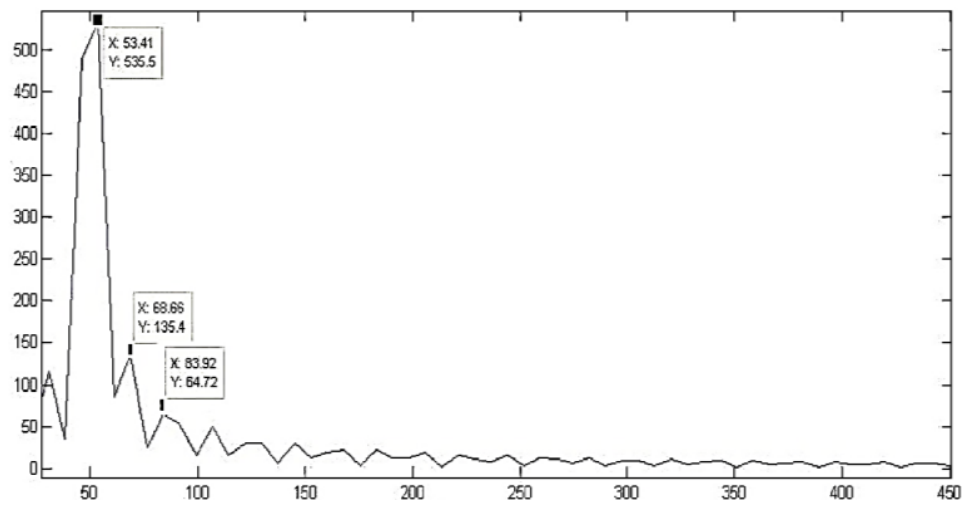

(a)

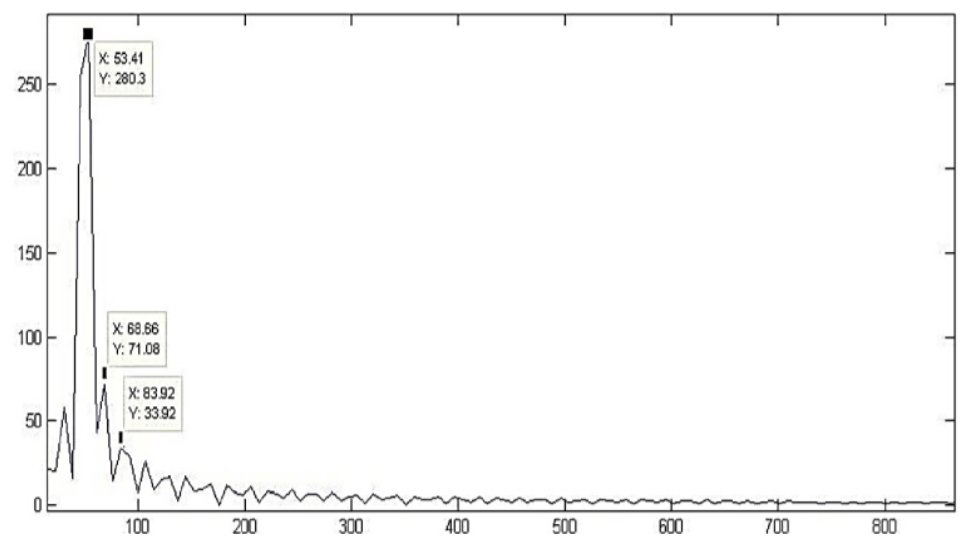

(b)

Figure 6. Occurred at balance load at $7 \mathrm{~km}$, evaluate FFT fault current wave; (a) $R F=25 \Omega$ and (b) $R F=50 \Omega$

In the same manner, the present fault wave for the remaining period was analyzed. On TL before, all failures were simulated after the study of the current wave using FFT. The importance of the two higher domains depends on the magnitude of the resistance and defect position for the present wave. Whenever the faulty position and the RF value is further down, the domain size should decrease as shown in Figure 7(a) and (b).

The fault resistance does not change frequency and stays stable $\mathrm{HZ}(53,68.66$, and 83.92) at low three domains from the calculation of the upper three domains to the loss present wave observed. We get these equations through proven frequency:

$$
\begin{aligned}
& C I=\text { First domain } \times 53 \\
& C 2=\text { Second domain } \times 68.66 \\
& C 3=\text { Third domain } \times 83.92
\end{aligned}
$$

Finally, we've got seven results simulated on TL for every defect by evaluating the latest ATP/EMTP/MATLAB wave of defect from current fault $\left(I_{0}\right)$ measurements in (ATP) and three domains higher. Additions to repeated the domain by using the FFT MATLAB for that domain when the failure takes place at 7 kilometers for all the other distances, as shown in Tables 2, 3 and 4. 
Table 2. Displays all data obtained during the $7 \mathrm{~km}$ failure network without load

\begin{tabular}{cccccccc}
\hline$R$ in $\Omega$ & $I_{0}$ & First domain & Second domain & Third domain & \multicolumn{1}{c}{$C I$} & \multicolumn{1}{c}{$C 2$} & \multicolumn{1}{c}{$C 3$} \\
\hline 0 & 4798.2 & 3230 & 669.6 & 233.9 & 172514.3 & 45974.736 & 19631.227 \\
25 & 755.4 & 535.5 & 135.4 & 64.72 & 28601.055 & 9296.564 & 5431.9496 \\
50 & 393.25 & 280.3 & 71.08 & 33.92 & 14970.823 & 4880.3528 & 2846.9056 \\
75 & 266.57 & 190.2 & 48.05 & 23.06 & 10158.582 & 3299.113 & 1935.4258 \\
100 & 202.1 & 144.3 & 36.26 & 17.55 & 7707.063 & 2489.6116 & 1472.9715 \\
\hline
\end{tabular}

Table 3. Displays all data obtained during the $7 \mathrm{~km}$ failure network without load network balance load

\begin{tabular}{cccccccc}
\hline$R$ in $\Omega$ & $I_{0}$ & First domain & Second domain & Third domain & $C I$ & \multicolumn{1}{c}{$C 2$} & $C 3$ \\
\hline 0 & 4798.1 & 3230 & 669.7 & 233.9 & 172514.3 & 45981.602 & 19631.227 \\
25 & 755.09 & 535.1 & 135.4 & 64.77 & 28579.691 & 9296.564 & 5436.1461 \\
50 & 392.91 & 279.9 & 71.04 & 33.97 & 14949.459 & 4877.6064 & 2851.1021 \\
75 & 266.38 & 189.9 & 48.02 & 23.09 & 10142.559 & 3297.0532 & 1937.9437 \\
100 & 201.78 & 143.9 & 36.21 & 17.59 & 7685.699 & 2486.1786 & 1476.3287 \\
\hline
\end{tabular}

Table 4. Displays all data obtained during the $7 \mathrm{~km}$ failure network without load network unbalance load

\begin{tabular}{cccccccc}
\hline$R$ in $\Omega$ & $I_{0}$ & First domain & Second domain & Third domain & \multicolumn{1}{c}{$C I$} & \multicolumn{1}{c}{$C 2$} & \multicolumn{1}{c}{$C 3$} \\
\hline 0 & 4798.1 & 3230 & 669.7 & 233.9 & 172514.3 & 45981.6 & 19631.2 \\
25 & 755.2 & 535.2 & 135.4 & 64.76 & 28585.032 & 9296.56 & 5435.3 \\
50 & 393.04 & 280 & 71.05 & 33.96 & 14954.8 & 4878.2 & 2850.26 \\
75 & 266.26 & 189.8 & 48.01 & 23.11 & 10137.218 & 3296.36 & 1939.62 \\
100 & 201.9 & 144 & 36.23 & 17.58 & 7691.04 & 2487.55 & 1475.48 \\
\hline
\end{tabular}

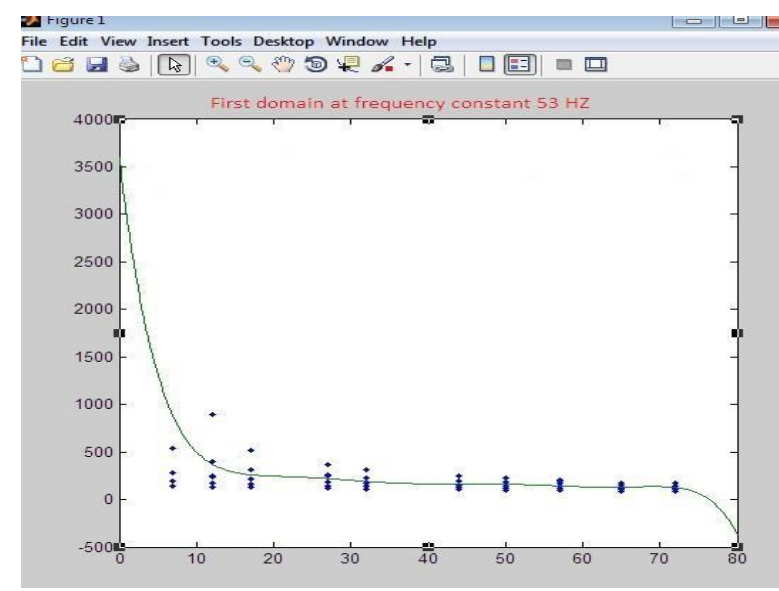

(a)

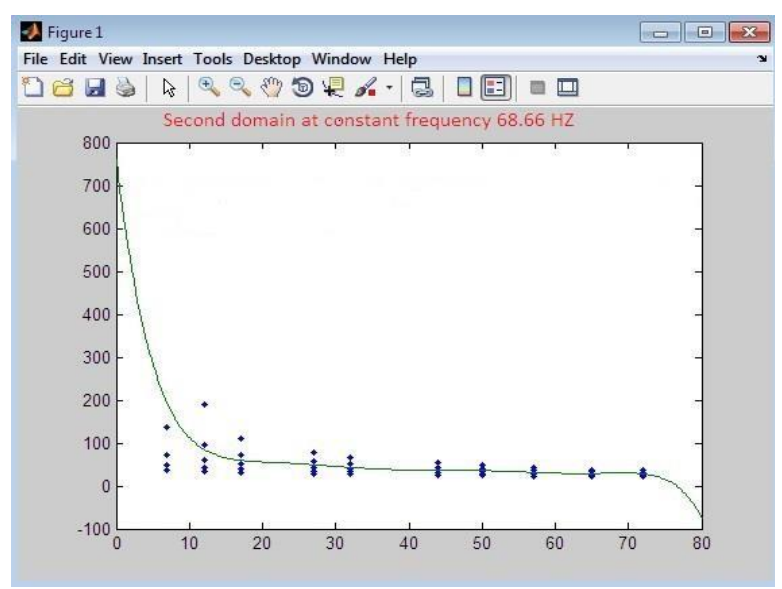

(b)

Figure 7. For relationship between fault location and magnitude of wave domain; (a) first domain and (b) second domain

\subsection{Neural network (NN) in MATLAB}

After all data were simulated for all defects, the data were checked on NN to determine the fault position from such results and to create a Simulink circuit to identify the real flaw in the future on MV network. Due to the fact that the 150 loss was simulated on the network and 7 data were obtained by calculating and measurement of wave current, the input data was positioned as a matrix 150/7. When data in $\mathrm{NN}$ were checked to find any defects simulated in TL, the cumulative regression results of training validation and testing were found to be 0.99907 .

By contrasting the fault position on the TL and the fault location on the NN test data for the same fault, a very slight discrepancy has been found between the two positions. The highest error is $2.3790 \mathrm{~km}$ and $1.7663 \mathrm{~km}$. The relation between fault positions simulated on TL place defects based on checked Data in NN is seen in Tables 5, 6, and 7. 
Table 5. Displays network at network without load

\begin{tabular}{cccccccc}
\hline$R$ in $\Omega$ & $I_{0}$ & First domain & Second domain & Third domain & \multicolumn{1}{c}{$C I$} & \multicolumn{1}{c}{$C 2$} & \multicolumn{1}{c}{$C 3$} \\
\hline 0 & 4798.2 & 3230 & 669.6 & 233.9 & 172514.3 & 45974.736 & 19631.227 \\
25 & 755.4 & 535.5 & 135.4 & 64.72 & 28601.055 & 9296.564 & 5431.9496 \\
50 & 393.25 & 280.3 & 71.08 & 33.92 & 14970.823 & 4880.3528 & 2846.9056 \\
75 & 266.57 & 190.2 & 48.05 & 23.06 & 10158.582 & 3299.113 & 1935.4258 \\
100 & 202.1 & 144.3 & 36.26 & 17.55 & 7707.063 & 2489.6116 & 1472.9715 \\
\hline
\end{tabular}

Table 6. Displays network at network balance load

\begin{tabular}{cccccccc}
\hline$R$ in $\Omega$ & $I_{0}$ & First domain & Second domain & Third domain & $C I$ & $C 2$ & $C 3$ \\
\hline 0 & 4798.1 & 3230 & 669.7 & 233.9 & 172514.3 & 45981.602 & 19631.227 \\
25 & 755.09 & 535.1 & 135.4 & 64.77 & 28579.691 & 9296.564 & 5436.1461 \\
50 & 392.91 & 279.9 & 71.04 & 33.97 & 14949.459 & 4877.6064 & 2851.1021 \\
75 & 266.38 & 189.9 & 48.02 & 23.09 & 10142.559 & 3297.0532 & 1937.9437 \\
100 & 201.78 & 143.9 & 36.21 & 17.59 & 7685.699 & 2486.1786 & 1476.3287 \\
\hline
\end{tabular}

Table 7. Displays network at network unbalance load

\begin{tabular}{cccccccl}
\hline$R$ in $\Omega$ & $I_{0}$ & First domain & Second domain & Third domain & $C I$ & \multicolumn{1}{c}{$C 2$} & \multicolumn{1}{c}{$C 3$} \\
\hline 0 & 4798.1 & 3230 & 669.7 & 233.9 & 172514.3 & 45981.6 & 19631.2 \\
25 & 755.2 & 535.2 & 135.4 & 64.76 & 28585.032 & 9296.56 & 5435.3 \\
50 & 393.04 & 280 & 71.05 & 33.96 & 14954.8 & 4878.2 & 2850.26 \\
75 & 266.26 & 189.8 & 48.01 & 23.11 & 10137.218 & 3296.36 & 1939.62 \\
100 & 201.9 & 144 & 36.23 & 17.58 & 7691.04 & 2487.55 & 1475.48 \\
\hline
\end{tabular}

When all fault locations were correlated with all fault locations, NN noticed that they have a linear connection as seen in Figure 8. And it is easy, after calculating and analysing the current motion, to measure the cumulative error of all fault simulations on the network and all faults with $\mathrm{NN}$ algorithms.

Total error $=\frac{\sum_{1}^{150}|\mathrm{D} 1-\mathrm{D} 2|}{150}$ Total error $=\frac{107.984884}{150}=0.719899227 \mathrm{~km}$

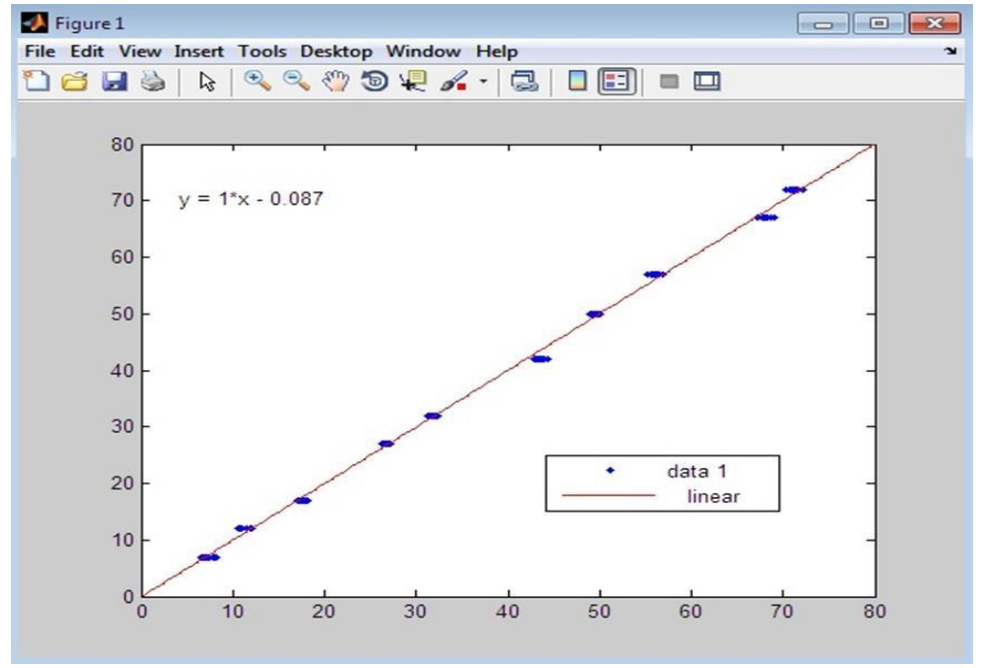

Figure 8. Relationship between fault simulated and fault detected in NN

In comparison, the cumulative loss of all errors replicated in the MV network was very little relative to locations with all errors at all locations. It has a very large duty to identify every fault position simulated in TL for the data checked in NN. After the analysis of current waves for that defect, the Simulink circuit was generated from data by means of NN to detect the actual fault in TL. The circuit is used to detect fault position in the substation from the control room after a fault occurs in the same way before, and seven different elements are obtained from measuring or analyzing the fault current. Test the circuit for the location of the error when resistance to earth $\mathrm{RF}=40$ at destance $27 \mathrm{~km}, \mathrm{RF}=65$ at destance $52 \mathrm{~km}$ away as shown in Figure 9(a) and (b). 


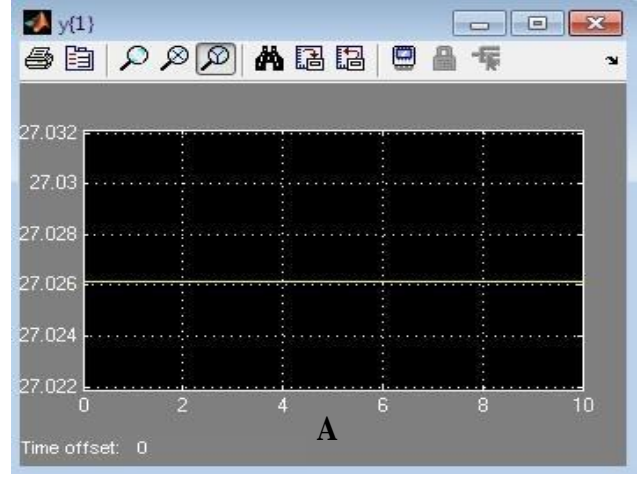

(a)

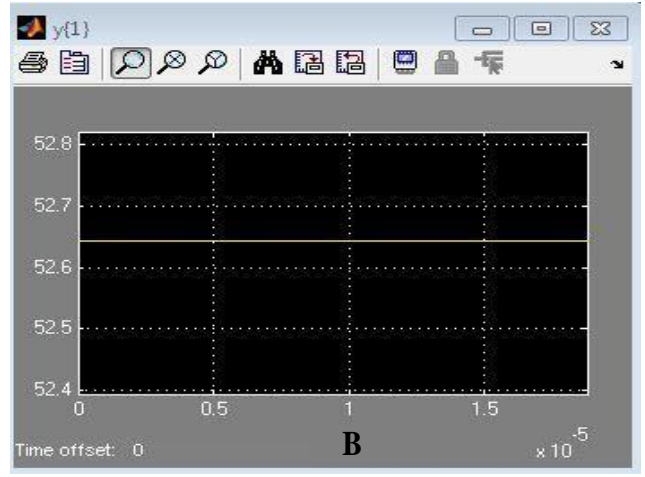

(b)

Figure 9. The circuit for the location of the error; (a) $\mathrm{RF}=40$ at destance $27 \mathrm{~km}$ and (b) $\mathrm{RF}=65$ at destance $52 \mathrm{~km}$

\section{CONCLUSION}

In today's environment, electricity is more and more needed and necessary to ensure a acceptable standard of reliability and protection. As long as the SLG is typical from any other faults in the electrical network, modern innovations are required to secure and regulate the power scheme. In this paper, a method used to diagnose a fault position after fault was detected to cut line from the network as quickly as possible has been established. Return to the network in order not to affect other lines and maintenance. Moreover, the costs of this process are reduced. This begins on the basis of the machine and the MV network emulation. five times at any stage with an increase in earth resistance from 0 to $100 \Omega$, ATP/EMTP simulation fault at ten points on the main line at various positions is applied. ATP/EMTP program simulates all faults. Earth resistance was changed several times as the value of earth resistance could not be known in the event of fault. The current failure wave has been measured and this wave has been analyzed with the FFT in MATLAB for input data production. Fault position estimates were developed with MATLAB tools, on the other hand. Models were conditioned and then checked with specific. The data collection and the fault position were exceptionally reliable on the cable. The difference between prediction and real performance of NN algorithm is less than $3 \%$. It means that both the fault definition and the fault position calculation have a reasonable consistency in the proposed technologies. In fact, a new generation of sophisticated fault locators may use the NN algorithm. Finally, the NN-algorithm created the Simulink circuit to detect a real defect when it happens in the future on MV.

\section{ACKNOWLEDGEMENTS}

The authors would like to thank the Ministry of Higher Education and Scientific Research of Iraq, University of Anbar, University Headquarter, Department of Construction and Projects \& College of Computer Science and Information Technology, University of Anbar, Ramadi, Iraq, for supporting as for applied this work.

\section{REFERENCES}

[1] J. Chen, "Fault Section Identification for Power Distribution Systems Using Online Measurements," Master's Thesis, Department Electrical and Computer Engineering, University of Kentucky, USA, 2015.

[2] U.-C. Force and S. Abraham, "Us-canada power system outage task force," Final report on the August 14, 2003 Blackout in the United States and Canada: Causes and recommendations, 2004.

[3] S. B. Mohod and V. N. Ghate, "Techniques for Detection of Power Quality Disturbance Waveform-A Review," Int. J. Electr. Electron. Comput. Syst., vol. 8, no. 2, pp. 563-567, 2012.

[4] A. D. Filomena, M. Resener, R. H. Salim, and A. S. Bretas, "Distribution systems fault analysis considering fault resistance estimation," Int. J. Electr. Power \& Energy Syst., vol. 33, no. 7, pp. 1326-1335, 2011, doi: 10.1016/j.ijepes.2011.06.010.

[5] Y. Zhang, Z. Wang, and J. Zhang, "Universal characteristics of faults in complex power system," Int. Rev. Electr. Eng., vol. 6, no. 3, 2011.

[6] Z. Li, X. Nan, and J. Tong, "Fault location methods for single-phase ground faults in neutral ungrounded system," Proceedings of the Chinese Society of Universities for Electric Power System and its Automation, vol. 4, no. 008, 2010. 
[7] M. M. Saha, J. J. Izykowski, and E. Rosolowski, Fault location on power networks, Berlin, Germany: Springer Science \& Business Media, 2009, doi: 10.1007/978-1-84882-886-5.

[8] Z. Yujun and W. Xiaowei, "Research on wavelet neural network for fault location in power distribution network," in Electrical, Information Engineering and Mechatronics 2011, Springer, pp. 1049-1057, 2012, doi: 10.1007/9781-4471-2467-2 124.

[9] D. Jansson and P. Wadström, "Study of system earthing for $36 \mathrm{kV}$ collector grids for wind farms," Master's Thesis, Department of Energy and Environment, Chalmers University of Technology, Gothenburg, Sweden, 2014.

[10] T. Baldwin, D. Kelle, J. Cordova, and N. Beneby, "Fault locating in distribution networks with the aid of advanced metering infrastructure," 2014 Clemson University Power Systems Conference, 2014, pp. 1-8, doi: 10.1109/PSC.2014.6808108.

[11] N. S. Coleman, C. Schegan, and K. N. Miu, "A study of power distribution system fault classification with machine learning techniques," 2015 North American Power Symposium (NAPS), 2015, pp. 1-6, doi: 10.1109/NAPS.2015.7335264.

[12] R. Salat and S. Osowski, "Accurate fault location in the power transmission line using support vector machine approach," in IEEE Transactions on Power Systems, vol. 19, no. 2, pp. 979-986, May 2004, doi: 10.1109/TPWRS.2004.825883.

[13] P. Ray, B. K. Panigrahi, and N. Senroy, "Extreme learning machine based fault classification in a series compensated transmission line," 2012 IEEE International Conference on Power Electronics, Drives and Energy Systems (PEDES), 2012, pp. 1-6, doi: 10.1109/PEDES.2012.6484297.

[14] P. K. Dash, S. R. Samantaray, and G. Panda, "Fault classification and section identification of an advanced seriescompensated transmission line using support vector machine," IEEE Trans. Power Deliv., vol. 22, no. 1, pp. 67-73, 2007, doi: 10.1109/TPWRD.2006.876695.

[15] K. Wang, W. Chen, and Q. Li, "Power system fault identification method based on multi-wavelet packet and artificial neural network", Proc. 2012 Int. Conf. Intell. Syst. Des. Eng. Appl. ISDEA, 2012, pp. 1457-1462, doi: 10.1109/ISdea.2012.421.

[16] N. Gana, N. F. Ab Aziz, Z. Ali, H. Hashim, and B. Yunus, "A comprehensive review of fault location methods for distribution power system," Indonesian Journal of Electrical Engineering and Computer Science (IJEECS), vol. 6, no. 1, pp. 185-192, 2017, doi: 10.11591/ijeecs.v6.i1.pp185-192.

[17] O. W. Chuan, N. F. Ab Aziz, Z. M. Yasin, N. A. Salim, and N. A. Wahab, "Fault classification in smart distribution network using support vector machine," Indonesian Journal of Electrical Engineering and Computer Science (IJEECS), vol. 18, no. 3, pp. 1148-1155, 2020, doi: 10.11591/ijeecs.v18.i3.pp1148-1155.

[18] S. S. Gururajapathy, H. Mokhlis, and H. A. Illias, "Fault location using mathematical analysis and database approach," COMPEL - Int. J. Comput. Math. Electr. Electron. Eng., vol. 38, no. 1, pp. 415-430, 2019, doi: 10.1108/COMPEL-02-2018-0077.

[19] H. H. Goh et al., "Transmission line fault detection: A review," Indonesian Journal of Electrical Engineering and Computer Science (IJEECS), vol. 8, no. 1, pp. 199-205, 2017, doi: 10.11591/ijeecs.v8.i1.pp199-205.

[20] M. Kaliwoda, B. Keune, N. Tomin, and C. Rehtanz, "Fault detection, identification and localization in mediumvoltage networks using fuzzy-logic," 12th IET Int. Conf. Dev. Power Syst. Prot. DPSP, 2014, pp. 1-6, doi:10.1049/cp.2014.0049.

[21] A. Azriyenni, M. M. Wazir, and Z. Naila, "Fuzzy Neural Network for Classification Fault In Protection System," Indonesian Journal of Electrical Engineering and Computer Science (IJEECS), vol. 12, no. 8, pp. 5969-5975, 2014, doi: 10.11591/ijeecs.v12.i8.pp5969-5975.

[22] G. V. Raju and E. Koley, "Fuzzy logic based fault detector and classifier for three phase transmission lines with STATCOM," Int. Conf. Electr. Power Energy Syst. ICEPES, 2017, pp. 469-474, doi: 10.1109/ICEPES.2016.7915976.

[23] M. R. Adzman, "Earth fault distance computation methods based on transients in power distribution systems," Doctoral Dissertations, Department of Electrical Engineering and Automation, Aalto University, Espoo, Finlandia, 2014.

[24] S. H. S. Barakat, "Fault detection classification and location in Underground Cables," Master Thesis, Electrical Power Engineering Fayoum University, Fayoum, Egypt 2014.

[25] Y. Fang, Y. Xue, H. Song, T. Guan, F. Yang, and B. Xu, "Transient energy analysis and faulty feeder identification method of high impedance fault in the resonant grounding system," in Proc. CSEE, vol. 38, 2018, pp. 5636-5645.

[26] E. B. M. Tayeb and O. A. A. A. Rhim, "Transmission line faults detection, classification and location using artificial neural network," Proc. 2011 Int. Conf. Util. Exhib. Power Energy Syst. Issues Prospect. Asia, ICUE 2011, 2012, pp. 1-5, doi: 10.1109/ICUEPES.2011.6497761.

[27] M. Oleskovicz, D.V. Coury and R.K. Aggarwal, "A Complete Scheme for Fault Detection, Classification and Location in Transmission Lines Using Neural Network," 7th International Conference on Developments in Power Systems Protection (DPSP 2001), no. 479, 2001, pp. 335-338, doi:10.1049/cp:20010168.

[28] I. Niazy and J. Sadeh, "A new single ended fault location algorithm for combined transmission line considering fault clearing transients without using line parameters," Int. J. Electr. Power Energy Syst., vol. 44, no. 1, pp. 816-823, 2013, doi: 10.1016/j.ijepes.2012.08.007. 


\section{BIOGRAPHIES OF AUTHORS}
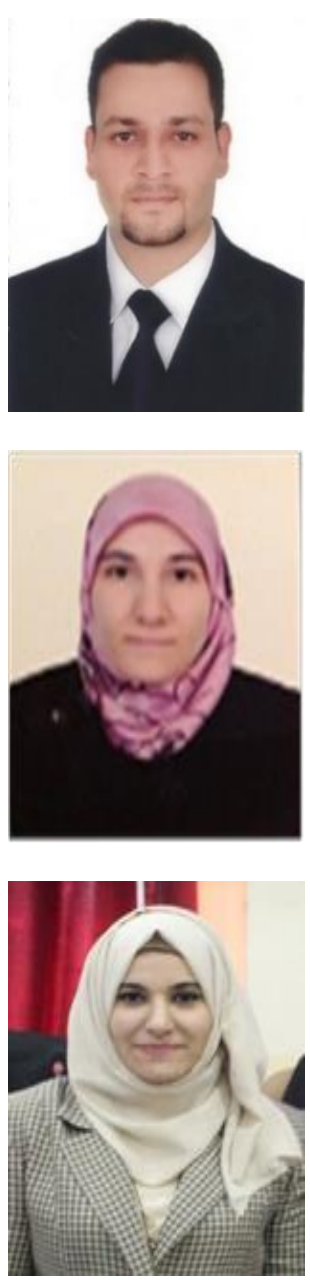

Ahmed Khudhair Abbas received his bachelor's degree in the Department of Electrical Power Techniques Engineering from the Al-Mamon University College in Baghdad, (2012). Where he also obtained his Master of Science (M.Sc.) degree in 2015 in school of Electrical system engineering (Electrical Power Engineering) from University Malaysia Perlis (UniMAP) in Malaysia. In 2016, he became an assistant lecturer in Anbar University. He is presently working in a University Headquarter, Construction and Projects Department in Anbar University, Iraq. His areas of interest are Power Quality, Control Systems engineering, Power Electronics, MATLAB Simulation, Renewable Energy Technologies, and Power System Protection

Sumaya Hamad received the B.Sc. (good) (first class) degree in computer science from University of Anbar, Anbar, Iraq, in 2002, and the M.Sc. degree in computer science from University of Anbar, Anbar, Iraq, in 2012. She is currently PhD student in Computer Science Department at University of Technology, Baghdad, Iraq, and she an Assist. Teacher at the College of Computer Science and Information Technology, University of Anbar. She has published 6 refereed journal and conference papers. Her current research interests include mobile computing, artificial intelligence, Ad Hoc networks, search engines, and information technology.

Nuha A. Hamad received the B.Sc. degree in computer science from University of Anbar, Anbar, Iraq, in 2009, and the M.Sc. degree in computer science from University of Anbar, Anbar, Iraq, in 2020. She an Assist. Lecturer at the University headquarter, University of Anbar. She has published 2 refereed journal and conference papers. Her current research interests include, artificial intelligence, security, and data mining. 